\title{
Pharmacological Therapy for Presbyopia in Patients with Previous Corneal Refractive Surgery: A Pilot Study
}

\author{
Veronica Vargas $\cdot$ Felipe Vejarano $\cdot$ Jorge Alió
}

Received: May 5, 2020 / Accepted: September 4, 2020 / Published online: September 23, 2020

(C) The Author(s) 2020

\begin{abstract}
Purpose: To perform a pilot evaluation of a novel pharmacological therapy for presbyopia in patients with previous corneal refractive surgery.

Methods: This interventional study included 130 presbyopic patients. The patients were divided into three groups: (1) LASIK group, which included patients with previous LASIK for myopia or hyperopia; (2) previous presbyopia surgery group, including patients with previous monovision or PresbyLASIK (PresbyMAX, SCHWIND eye-tech-solutions GmbH, Kleinostheim, Germany); and (3) control group,
\end{abstract}

Digital Features This article is published with digital features to facilitate understanding of the article. To view digital features for this article go to https://doi.org/ 10.6084/m9.figshare.12912281.

V. Vargas · J. Alió $(\bowtie)$

Cornea, Cataract and Refractive Surgery

Department, VISSUM, Alicante, Spain

e-mail: jlalio@vissum.com

V. Vargas · J. Alió

Research, Investigation \& Development

Department, VISSUM, Alicante, Spain

F. Vejarano

Fundación Oftalmológica Vejarano, Popayán,

Colombia

J. Alió

Department of Ophthalmology, School of Medicine,

Universidad Miguel Hernández, Alicante, Spain which included presbyopes without any corneal refractive procedure. The main reason for dividing them into groups is that we hypothesized that the previous presbyopia surgery group may have better outcomes as the patients already have an increased depth of field. The uncorrected near and distance visual acuity was measured before and 2 hours after the binocular instillation of the eye drop (FOV tears), as well as the objective scatter index (OSI), and pupil diameter in photopic and scotopic conditions. Side effects were reported as well.

Results: There was a statistically significant improvement in the uncorrected near vision in all groups $(p=0.001)$. Ninety-one percent of the patients included in this study gained at least one line in near vision. All patients in the previous presbyopia surgery group gained at least one line in near vision. Six patients (13.9\%) in the LASIK group and five $(7.6 \%)$ in the control group did not gain any lines of near vision. There was no significant difference in the OSI, there was a significant change in pupil size in scotopic conditions in all groups $(p=0.001)$, and $5.3 \%$ of the patients reported having a headache as a side effect of the therapy.

Conclusions: Topical treatment with this pharmacological therapy offers a potential for near vision improvement in patients with previous corneal refractive surgery, especially in those with previous presbyopia surgery. 
Keywords: Corneal refractive surgery; Depth of field; Multifocal cornea; Pharmacological therapy of presbyopia; Presbyopia; Uncorrected near vision

\section{Key Summary Points}

\section{Why carry out this study?}

We decided to carry out this study because the correction of presbyopia remains a challenge for the refractive surgeon; to date, we have not been able to restore accommodation.

A noninvasive approach (like topical medication) seems an attractive option because it is also reversible.

The hypothesis of the study was that the patients with previous presbyopia surgery would gain more lines of near vision than the patients in the control group and patients with previous hyperopic or myopic LASIK.

\section{What was learned from the study?}

Near vision improved at least one line in more than $90 \%$ of the patients; 11 patients in the previous LASIK and control group did not gain any lines of near vision after the binocular instillation of the eye drop.

What we learned from this study is that patients with previous presbyopia surgery benefit the most of the topical therapy as they all gained lines in near vision, which corroborated our hypothesis.

\section{DIGITAL FEATURES}

To view digital features for this article go to https://doi.org/10.6084/m9.figshare.12912281.

\section{INTRODUCTION}

The loss of accommodation begins early in life and becomes clinically manifest around age 40 [1], impairing daily life activities like reading. It has been estimated that by 2020, 1.37 billion people will be affected by presbyopia [2], so its correction is necessary as it represents an economic burden [3] and has a negative impact on quality of life [4].

Unlike all other refractive errors (myopia, hyperopia and astigmatism), presbyopia correction remains a challenge for the refractive surgeon, as complete restoration of accommodation has not yet been achieved [5]. All surgical techniques that restore near vision are based on pseudoaccommodation, including laser in situ keratomileusis (LASIK) monovision, PresbyLASIK, corneal inlays, and multifocal or extended depth of focus intraocular lenses (IOLs). The improvement in near vision in pseudoaccommodation is secondary to an increase in the depth of field [1].

Accommodation is the dioptric change in optical power of the eye which allows us to focus from far to near [1]. Accommodation can be pharmacologically stimulated by the contraction of the ciliary muscle. Some topical treatments have been studied [6-10], reporting an improvement in near vision with the topical application of muscarinic cholinergic agonists. We previously reported our results with a new pharmacological therapy (FOV tears) for presbyopia $[8,9]$. The aim of this study is to report the near visual outcomes and evaluate the potential of FOV tears in patients with previous corneal refractive surgery. We hypothesized that patients with previous presbyopia surgery would gain more lines in near vision than patients with previous LASIK or the control group.

\section{METHODS}

This is a single-center prospective, consecutive, non-randomized, interventional, comparative series of cases. The study was performed according to the tenets of the Declaration of Helsinki of 1964, as revised in 2013 (Fortaleza, 
Brazil). The protocol was reviewed and approved by the Ethics Committee of Fundación Oftalmológica Vejarano in Popayán, Colombia. Informed consent was received from the patients involved in the study.

All participants had a slit-lamp biomicroscopy and fundus examination before being eligible for the study.

Inclusion criteria: patients older than 40 years with previous LASIK, presbyLASIK or monovision, that were spectacle-dependent for near vision activities, or were not satisfied with their near vision after surgery.

Exclusion criteria included patients with myopia $>2$ diopters (D) and/or astigmatism $>1.5 \mathrm{D}$, pseudophakia, dry eye, pupil irregularities, glaucoma, retinal conditions (especially any susceptibility to retinal detachment) and any known sensitivity to the components of the pharmacological compound (FOV tears).

Patients were divided into three groups: (1) LASIK group, which included patients with previous LASIK for myopia and hyperopia; (2) previous presbyopia surgery group, including patients with previous presbyLASIK and monovision; and (3) control group, which included presbyopes without any previous corneal refractive procedure. This division was based on the hypothesis that patients in the previous presbyopia surgery group would have a better near visual outcome due to the extended depth of field they already had.

We evaluated the binocular uncorrected distance and near visual acuity (UDVA, UNVA), corrected distance visual acuity (CDVA), manifest refraction, intraocular scattering and pupil size under photopic and scotopic conditions before and 2 hours (h) after the binocular instillation of the eye drop.

Distance vision was measured using the Early Treatment of Diabetic Retinopathy Study (ETDRS) chart at $4 \mathrm{~m}$. Near vision was measured at a distance of $40 \mathrm{~cm}$ using a handheld Rosenbaum chart with Jaeger notation which was converted to a $\log$ MAR algorithm. To maintain the correct reading distance, the chart had a $40 \mathrm{~cm}$ cord attached.

A double-pass instrument (OQAS, Visiometrics SL, Spain) was used to quantify the magnitude of intraocular scattering (objective scatter index, OSI). Pupil diameter under photopic and scotopic conditions was measured using an AL-Scan optical biometer (Nidek Co., Ltd., Japan).

The FOV tears contain pilocarpine $0.247 \%$, phenylephrine $0.78 \%$, polyethylene glycol $0.09 \%$, nepafenac $0.023 \%$, pheniramine $0.034 \%$, and naphazoline $0.003 \%$. The eye drop was prepared by a qualified pharmacy (notice of allowance in the USA, number 2951).

The primary outcomes were the UDVA and UNVA. Secondary outcomes were: CDVA, manifest refraction, intraocular scattering and pupil size under photopic and scotopic conditions.

All data were registered in a protocol and analyzed by independent observers (JLA, VV).

Side effects after the instillation of the eye drop such as burning sensation, redness and headaches were documented as well.

\section{Statistical Analysis}

The statistical analysis was performed using SPSS software for Windows (version 15.0.1). The average values and standard deviations were calculated for every parameter during the follow-up. Normality of all data samples was evaluated by means of the Kolmogorov-Smirnov test. When parametric analysis was possible, the Student $t$ test for paired data was performed for all parameter comparisons between pre-eye drop and post-eye drop examinations. When parametric analysis was not possible, the Wilcoxon test was applied to assess the significance of differences between pre-eye drop and post-eye drop data. For all statistical tests, a $p$ value less than 0.05 was considered statistically significant.

\section{RESULTS}

This study included 130 patients (59 female and 71 male). Forty-three patients were included in the LASIK group, 22 patients in the previous presbyopia surgery group and 65 patients in the control group. Table 1 shows the patient demographics. A statistically significant 
Table 1 Patient demographics

\begin{tabular}{|c|c|c|c|c|c|}
\hline & \multirow{2}{*}{ Number of patients } & \multirow{2}{*}{$\begin{array}{l}\text { Age } \\
\text { Mean } \pm \text { SD }\end{array}$} & \multicolumn{2}{|c|}{ Gender } & \multirow{2}{*}{$\begin{array}{l}\text { Lines gained UNVA } \\
\text { Mean } \pm \text { SD }\end{array}$} \\
\hline & & & Male & Female & \\
\hline Control group & 65 & $50.0 \pm 5.1$ & 41 & 24 & $1.7 \pm 0.9$ \\
\hline \multicolumn{6}{|l|}{ LASIK group } \\
\hline Total & 43 & $51.1 \pm 5.6$ & 21 & 22 & $1.5 \pm 1.0$ \\
\hline Hyperopic LASIK & 20 & $53.0 \pm 5.9$ & 10 & 10 & $1.8 \pm 1.1$ \\
\hline Myopic LASIK & 23 & $49.4 \pm 4.9$ & 11 & 12 & $1.2 \pm 1.0$ \\
\hline \multicolumn{6}{|c|}{ Presbyopia surgery group } \\
\hline Total & 22 & $58.0 \pm 5.6$ & 9 & 13 & $1.9 \pm 1.0$ \\
\hline Monovision & 8 & $56.1 \pm 3.9$ & 4 & 4 & $2.0 \pm 1.3$ \\
\hline PresbyLASIK & 14 & $60.5 \pm 5.9$ & 5 & 9 & $1.8 \pm 0.86$ \\
\hline
\end{tabular}

$U N V A$ uncorrected near visual acuity, $S D$ standard deviation

difference was found in UDVA, UNVA and scotopic pupil size in the LASIK group $2 \mathrm{~h}$ after the instillation of the eye drop (see Tables 2 and 3). Forty-one percent of the patients in this group gained one line of near vision, and six patients did not gain any lines of near vision.

Patients in the previous presbyopia surgery group had a statistically significant difference in UNVA and photopic pupil size after the instillation of the eye drop (see Tables 4 and 5). All of the patients in this group gained at least one line in near vision.
Patients in the control group had a statistically significant difference in UDVA, UNVA and pupil size under photopic and scotopic conditions after the instillation of the eye drop (see Tables 6 and 7). Forty-three percent of the patients in this group gained two lines of near vision, and five patients did not gain any lines of near vision. Figure 1 depicts the lines of near vision gained in each group.

No statistically significant change in secondary parameters including intraocular scattering, manifest refraction and photopic pupil

Table 2 Manifest refraction, intraocular scattering and pupil size under photopic and scotopic conditions before and $2 \mathrm{~h}$ after the binocular instillation of the eye drop in the LASIK group

\begin{tabular}{|c|c|c|c|c|c|c|}
\hline & \multicolumn{2}{|l|}{ Right } & \multirow[t]{2}{*}{$p$ value } & \multicolumn{2}{|l|}{ Left } & \multirow[t]{2}{*}{$p$ value } \\
\hline & $\begin{array}{l}\text { Before } \\
\text { Mean } \pm \text { SD }\end{array}$ & $\begin{array}{l}\text { After } \\
\text { Mean } \pm \text { SD }\end{array}$ & & $\begin{array}{l}\text { Before } \\
\text { Mean } \pm \text { SD }\end{array}$ & $\begin{array}{l}\text { After } \\
\text { Mean } \pm \text { SD }\end{array}$ & \\
\hline Sphere & $0.36 \pm 0.58$ & $0.36 \pm 0.66$ & 1.00 & $0.42 \pm 0.65$ & $0.32 \pm 0.60$ & 0.071 \\
\hline Cylinder & $-0.54 \pm 0.30$ & $-0.58 \pm 0.37$ & 0.332 & $-0.58 \pm 0.37$ & $-0.62 \pm 0.32$ & 0.301 \\
\hline OSI & $1.07 \pm 0.82$ & $1.07 \pm 0.81$ & 0.955 & $0.95 \pm 0.77$ & $1.01 \pm 0.97$ & 0.605 \\
\hline Photopic pupil & $3.22 \pm 0.74$ & $3.10 \pm 0.87$ & 0.361 & $3.07 \pm 0.76$ & $3.02 \pm 0.70$ & 0.654 \\
\hline Scotopic pupil & $4.5 \pm 0.78$ & $3.9 \pm 0.77$ & 0.001 & $4.5 \pm 0.82$ & $3.9 \pm 0.77$ & 0.001 \\
\hline
\end{tabular}

OSI objective scatter index, $S D$ standard deviation 
Table 3 Uncorrected distance and near visual acuity before and $2 \mathrm{~h}$ after the binocular instillation of the eye drop in the LASIK group

\begin{tabular}{llll}
\hline & Before & After & $\boldsymbol{p}$ value \\
\hline UDVA & $0.06 \pm 0.08$ & $0.03 \pm 0.05$ & 0.001 \\
UNVA & $0.25 \pm 0.17$ & $0.10 \pm 0.12$ & 0.001 \\
\hline
\end{tabular}

$U D V A$ uncorrected visual acuity, $U N V A$ uncorrected near visual acuity

size were observed in the LASIK or presbyopia surgery group (Tables 2,4 ).

Headache was presented as a side effect in seven patients $(5.3 \%)$; one of these patients was intolerant to the eye drop. No other side effects such as burning sensation or redness were reported.

\section{DISCUSSION}

The results of this study shows that near vision improved significantly in all groups $2 \mathrm{~h}$ after the instillation of the eye drop. These results correlate with those obtained in our previous studies $[8,9]$.

We found a significant difference in pupil size under scotopic conditions in all groups. This result is expected, because under scotopic conditions there is a physiological pupil dilation which could not have happened after the use of the eye drop due to the constriction of the pupillary sphincter secondary to the miotic effect of the pilocarpine [11]. Miosis might be a problem for those patients who work in dim light environments [12] due to the reduction in retinal illuminance [13], but it improves the depth of field by the pinhole effect [12]. Depth of field has been described as the range of viewing distance or dioptric power over which visual acuity performance is maintained [1]; it is dependent on pupil size and illumination level: the larger the pupil diameter, the smaller the depth of field, and vice versa [14]. Intermediate vision is also improved with pupillary miosis, and better image quality is achieved at high light levels [13].

The myopic shift that patients in the previous presbyopia surgery group presented is due to the accommodative myopia induced by pilocarpine. It has been reported that the instillation of $2 \%$ pilocarpine can induce an accommodative myopia of $5.84 \mathrm{D}$ in young patients (20-40 years old) [11]. Hyperopic patients are the ones that would benefit the most by this myopic shift.

The magnitude of accommodative response after a topical treatment depends on intraocular pharmacokinetics, drug concentration and iris pigmentation $[14,15]$. These could be the reasons that 11 patients (in the LASIK and control groups) did not gain any lines of near vision. Wold et al. [15] reported that patients with light irides had greater accommodative amplitude

Table 4 Manifest refraction, intraocular scattering and pupil size under photopic and scotopic conditions before and $2 \mathrm{~h}$ after the binocular instillation of the eye drop in the previous refractive surgery group

\begin{tabular}{|c|c|c|c|c|c|c|}
\hline & \multicolumn{2}{|l|}{ Right } & \multirow[t]{2}{*}{$p$ value } & \multicolumn{2}{|l|}{ Left } & \multirow[t]{2}{*}{$p$ value } \\
\hline & $\begin{array}{l}\text { Before } \\
\text { Mean } \pm \text { SD }\end{array}$ & $\begin{array}{l}\text { After } \\
\text { Mean } \pm \text { SD }\end{array}$ & & $\begin{array}{l}\text { Before } \\
\text { Mean } \pm \text { SD }\end{array}$ & $\begin{array}{l}\text { After } \\
\text { Mean } \pm \text { SD }\end{array}$ & \\
\hline Sphere & $0.18 \pm 0.76$ & $0.01 \pm 0.84$ & 0.007 & $0.25 \pm 0.72$ & $0.11 \pm 0.81$ & 0.117 \\
\hline Cylinder & $-0.65 \pm 0.34$ & $-0.64 \pm 0.39$ & 0.840 & $-0.68 \pm 0.36$ & $-0.64 \pm 0.39$ & 0.813 \\
\hline OSI & $1.27 \pm 1.02$ & $1.23 \pm 1.02$ & 0.754 & $1.59 \pm 1.99$ & $1.07 \pm 0.95$ & 0.226 \\
\hline Photopic pupil size & $3.34 \pm 0.83$ & $3.57 \pm 0.93$ & 0.334 & $3.34 \pm 0.72$ & $3.38 \pm 0.73$ & 0.794 \\
\hline Scotopic pupil size & $4.85 \pm 0.85$ & $4.09 \pm 0.98$ & 0.008 & $4.81 \pm 0.94$ & $3.96 \pm 0.88$ & 0.002 \\
\hline
\end{tabular}

$O S I$ objective scatter index, $S D$ standard deviation 
Table 5 Uncorrected distance and near visual acuity before and $2 \mathrm{~h}$ after the binocular instillation of the eye drop in the previous refractive surgery group

\begin{tabular}{llll}
\hline & Before & After & $\boldsymbol{p}$ value \\
\hline UDVA & $0.07 \pm 0.09$ & $0.05 \pm 0.08$ & 0.213 \\
UNVA & $0.32 \pm 0.17$ & $0.13 \pm 0.13$ & 0.001 \\
\hline
\end{tabular}

$U D V A$ uncorrected visual acuity, $U N V A$ uncorrected near visual acuity

than those with brown irides after the topical instillation of pilocarpine. This is due to the increased pigment epithelium in the ciliary muscle and iris (in patients with dark irides) which binds topically applied agents, decreasing their bioavailability [14].

Regarding the adverse effects, headache was the only one reported by the patients. Headache is a common side effect of pilocarpine and tends to disappear within several weeks [11].

As we hypothesized, all the patients from the previous presbyopia surgery group gained lines in near vision. The myopic shift that these patients had and the miotic effect of the eye drop enhanced the near vision by boosting their depth of field.

Our results correlate with the ones obtained with other topical therapies $[6,7,10]$.

Abdelkader [6] reported a four-line mean improvement in UNVA $1 \mathrm{~h}$ after instilling monocularly carbachol $2.25 \%$ with
Table 7 Uncorrected distance and near visual acuity before and $2 \mathrm{~h}$ after the binocular instillation of the eye drop in the control group

\begin{tabular}{llll}
\hline & Before & After & $\boldsymbol{p}$ value \\
\hline UDVA & $0.02 \pm 0.04$ & $0.00 \pm 0.03$ & 0.001 \\
UNVA & $0.36 \pm 0.15$ & $0.18 \pm 0.11$ & 0.001 \\
\hline
\end{tabular}

$U D V A$ uncorrected visual acuity, $U N V A$ uncorrected near visual acuity

brimonidine $0.2 \%$. The UNVA was measured with the Jaeger scale, and all the treated subjects abandoned the use of near glasses. He also compared the monocular instillation of $3 \%$ carbachol and $0.2 \%$ brimonidine in combined and separate forms, demonstrating a significant improvement in mean near visual acuity in the combined solution group [7]. Benozzi et al. [10] reported that $100 \%$ of patients achieved near vision of $\mathrm{J} 1$ after the topical instillation of pilocarpine $1 \%$ and $0.1 \%$ diclofenac.

One of the limitations of this study is its design as a pilot investigation. It was performed as a feasibility study, and the effects were evaluated over a short term. In a previous study [8], we evaluated the effects of the eye drop up to 1 month. We found no significant changes in tear film quality or endothelial cell count, and the patients tolerated the use of the eye drop. A longer follow-up that includes an objective measurement of accommodation to clarify

Table 6 Manifest refraction, intraocular scattering and pupil size under photopic and scotopic conditions before and $2 \mathrm{~h}$ after the binocular instillation of the eye drop in the control group

\begin{tabular}{|c|c|c|c|c|c|c|}
\hline & \multicolumn{2}{|l|}{ Right } & \multirow[t]{2}{*}{$p$ value } & \multicolumn{2}{|l|}{ Left } & \multirow[t]{2}{*}{$p$ value } \\
\hline & $\begin{array}{l}\text { Before } \\
\text { Mean } \pm \text { SD }\end{array}$ & $\begin{array}{l}\text { After } \\
\text { Mean } \pm \text { SD }\end{array}$ & & $\begin{array}{l}\text { Before } \\
\text { Mean } \pm \text { SD }\end{array}$ & $\begin{array}{l}\text { After } \\
\text { Mean } \pm \text { SD }\end{array}$ & \\
\hline Sphere & $0.36 \pm 0.44$ & $0.29 \pm 0.51$ & 0.125 & $0.36 \pm 0.45$ & $0.31 \pm 0.53$ & 0.370 \\
\hline Cylinder & $-0.40 \pm 0.32$ & $-0.44 \pm 0.30$ & 0.312 & $-0.36 \pm 0.45$ & $-0.40 \pm 0.28$ & 0.256 \\
\hline OSI & $0.76 \pm 0.71$ & $0.92 \pm 0.92$ & 0.243 & $0.60 \pm 0.38$ & $0.79 \pm 0.87$ & 0.073 \\
\hline Photopic pupil size & $3.3 \pm 0.56$ & $2.8 \pm 1.0$ & 0.001 & $3.2 \pm 0.56$ & $2.7 \pm 1.0$ & 0.001 \\
\hline Scotopic pupil size & $4.9 \pm 0.95$ & $3.8 \pm 0.83$ & 0.001 & $5.0 \pm 0.87$ & $3.9 \pm 0.96$ & 0.001 \\
\hline
\end{tabular}

OSI objective scatter index, SD standard deviation 

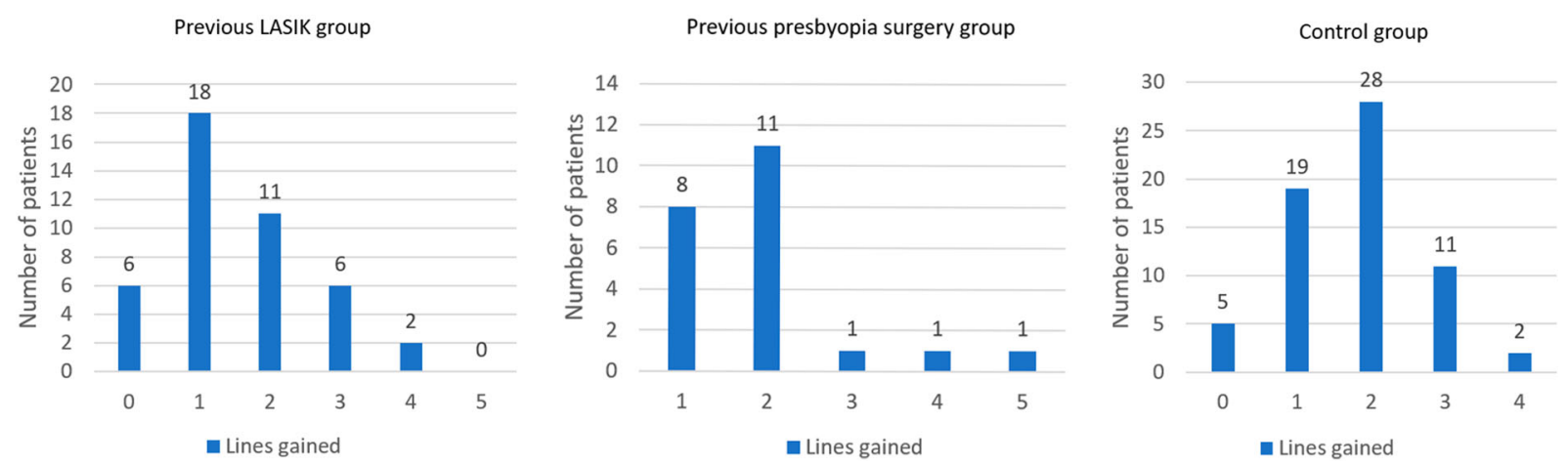

Fig. 1 Number of lines gained in near vision in the LASIK group, previous presbyopia surgery group and control group

whether the eye drop has an accommodative or pseudoacommodative effect is necessary. We did not perform any subjective measurements of accommodation because they tend to overestimate the optical change in power of the eye $[1,14]$. There is also the need to perform a survey with a validated questionnaire to evaluate whether there is any improvement in the patients' quality of life and whether they are satisfied with their near vision.

Dr. Vejarano prescribes the eye drop twice a day to all his patients for daily use, and up to $91 \%$ of them are satisfied with their near vision (personal communication).

To our knowledge, this is the first study to report the potential of this therapy, showing for the first time short-term outcomes of a topical pharmacological compound medication for the treatment of presbyopia in patients with previous corneal refractive surgery.

\section{CONCLUSIONS}

In conclusion, $91.5 \%$ of the patients included in this study improved at least one line of UNVA. Given that this is a reversible and noninvasive therapy, it would be an ideal treatment for presbyopia.

\section{ACKNOWLEDGEMENTS}

Funding. This study is supported by the Red Temática de Investigación Cooperativa en Salud
(RETICS), reference number RD16/0008/0012, funded by the Instituto de Salud Carlos III and co-funded by the European Regional Development Fund (ERDF), "A way to make Europe". No funding or sponsorship was received for the publication of this article.

Authorship. All named authors meet the International Committee of Medical Journal Editors (ICMJE) criteria for authorship for this article, take responsibility for the integrity of the work as a whole, and have given their approval for this version to be published.

Disclosures. Jorge Alió is a member of the journal's Editorial Board. Veronica Vargas has no conflict of interest. Felipe Vejarano owns the patent for the FOV tears.

Compliance with Ethics Guidelines. The study was performed according to the tenets of the Declaration of Helsinki of 1964, as revised in 2013 (Fortaleza, Brazil). The protocol was reviewed and approved by the Ethics Committee of Fundación Oftalmológica Vejarano in Popayán, Colombia. Informed consent was received from the patients involved in the study.

Data Availability. The data sets generated during and/or analyzed during the current study are available from the corresponding author on reasonable request.

Open Access. This article is licensed under a Creative Commons Attribution- 
NonCommercial 4.0 International License, which permits any non-commercial use, sharing, adaptation, distribution and reproduction in any medium or format, as long as you give appropriate credit to the original author(s) and the source, provide a link to the Creative Commons licence, and indicate if changes were made. The images or other third party material in this article are included in the article's Creative Commons licence, unless indicated otherwise in a credit line to the material. If material is not included in the article's Creative Commons licence and your intended use is not permitted by statutory regulation or exceeds the permitted use, you will need to obtain permission directly from the copyright holder. To view a copy of this licence, visit http:// creativecommons.org/licenses/by-nc/4.0/.

\section{REFERENCES}

1. Vargas V, Radner W, Allan B, Reinstein D, Burckhard D, Alió JL. Methods for the study of near, intermediate vision and accommodation: an overview of subjective and objective approaches. Surv Ophthalmol. 2019;64(1):90-100.

2. Holden BA, Fricke TR, Ho SM, Wong R, Schlenther G, Cronje S, Burnett A, Papas E, Naidoo KS, Frick KD. Global vision impairment due to uncorrected presbyopia. Arch Ophthalmol. 2008;126(12): 1731-9.

3. Frick KD, Joy SM, Wilson DA, Naidoo KS, Holden BA. The global burden of potential productivity loss from uncorrected presbyopia. Ophthalmology. 2015;122(8):1706-10.

4. Fricke TR, Tahhan N, Resnikoff S, Papas E, Burnett A, Ho SM, Naduvilath T, Naidoo KS. Global prevalence of presbyopia and vision impairment from uncorrected presbyopia. Systematic review, meta- analysis and modelling. Ophthalmology 2018;125 (10): 1492-1499.

5. Wolffsohn JS, Davies LN. Presbyopia: Effectiveness of correction strategies. Prog Retin Eye Res. 2019;68: 124-43.

6. Improved AA, Miotics PVW. Eye Contact Lens. 2015;41:323-7.

7. Abdelkader A, Kaufman, H.E. Clinical outcomes of combined versus separate carbachol and brimonidine drops in correcting presbyopia. Eye Vis (Lond). 2016; $5: 3,31$.

8. Renna A, Vejarano LF, De la Cruz E, Alio JL. Pharmacological treatment of presbyopia by novel binocularly instilled eye drops: a pilot study. Ophthalmol Ther. 2016;5:63-73.

9. Vargas V, Vejarano F, Alió JL. Near vision improvement with the use of a new topical compound for presbyopia correction: a prospective, consecutive, interventional non-comparative clinical study. Ophthalmol Ther. 2019;8(1):31-9.

10. Benozzi J, Benozzi G, Orman B. Presbyopia: a new potential pharmacological treatment. Med Hypothesis Discov Innov Ophthalmol. 2012;1(1): 3-5.

11. Zimmerman TJ, Wheeler TM. Miotics. Side effects and ways to avoid them. Ophthalmology. 1982;89: 76-80.

12. Zimmerman TJ. Pilocarpine. Ophthalmology. 1981;88:85-8.

13. Xu R, Wang H, Jaskulski M, et al. Small-pupil versus multifocal strategies for expanding depth of focus of presbyopic eyes. J Cataract Refract Surg. 2019;45(5):647-55.

14. Glasser A. Accommodation. In: Kaufman PL, editor. Adler's Physiology of the Eye. 11th edition. Saunders; 2011.p 40-70.

15. Wold JE, Hu A, Chen S, et al. Subjective and objective measurement of human accommodative amplitude. J Cataract Refract Surg. 2003;29:1878. 